THURSDAY, JUNE 7, $188_{3}$

\section{WIEDEMANN'S "ELECTRICITY"}

Die Lehre von der Electricität. Von Gustav Wiedemann. Vol. I., pp. xi. and 795 (I882); Vol. II., pp. vii. and IOO2 (I 883). (Braunschweig: Vieweg.)

FOR more than twenty years Prof. Wiedemann's "Lehre vom Galvanismus und Elektromagnetismus," first published in $186 \mathrm{I}$, has been recognised without question as the leading authority and great storehouse of facts on the branch of science of which it treats. It is a practically exhaustive treatise, and each of the two editions (second edition, 1872 to I 874 ) marks with wonderful accuracy the high-water mark of knowledge of its subject up to the date of publication. It is safe to assume that any fact that is not to be found recorded in its pages had not been discovered, or at least had not been published, up to the date of completion of whichever edition is examined. The fulness and accuracy of the references to original authorities give to Prof. Wiedemann's book a unique value also as a classified index to the literature of galvanic electricity and electromagnetism.

The work which forms the subject of this notice, is in one sense a third edition of the "Lehre vom Galvanismus." It apnears however under a new title, and is in fact to a great extent a new book. It is characteristic of the direction taken by the advance of electrical science during the last twenty years that, while Prof. Wiedemann found it practicable to confine himself in his first and second editions almost exclusively to the phenomena of current electricity and of magnetism, he has found it advisable in the present edition to enlarge the scope of his work so as to make it include the whole range of electrical science. It is true that the second edition contains an important chapter devoted to the discussion of a phenomenon that has usually been considered in connection with statical electricity, namely, the disruptive discharge in gases of different densities; but this is almost the only part of the book in which the considerations that have to be dealt with in treating of electrostatics occupy a prominent place. It is however becoming less and less possible to treat satisfactorily of one branch of electricity apart from the remainder. The terms frictional electricity and galvanic electricity have evidently an historical rather than a scientific origin. They do not refer to any logical classification of phenomena, but to two among the many processes by which electrical effects can be originated. It is not even by any means certain that electrification by friction is fundamentally a distinct phenomenon from electrification by contact as this occurs in a galvanic cell; on the contrary, various recent investigations tend to show that these actions are essentially similar, and that the friction which takes place in one case is of the nature of an accidental accompaniment. As a matter of fact, however, an electrical machine acting by friction serves (or at least did so until recently) as the readiest means of producing one large class of electrical phenomena; while a galvanic or voltaic battery serves (or at least did so until recently) as the readiest means of producing another large class of phenomena. Thus the division of electrical science for the purposes of study

VOL. XXVIIL.-No. 7 IO into frictional electricity and galvanic electricity originated in considerations of experimental convenience rather than in any strictly scientific distinction. So far as such a distinction can be drawn between these two branches, it may be said that the former includes the study of all those plienomena in which difference of potentials is the most characteristic factor; while the latter. includes the study of phenomena characterised by the transfer of electricity. As examined by the instruments in use fiveand-twenty years ago, the effects produced by the electrical machine seemed distinct enough from those due to the galvanic battery-indeed the difficulty rather was to establish their mutual connections; but with the galvanometers and electrometers that are now-thanks to Sir William Thomson-in the hands of every electrician, nothing is easier than to measure the current of an electrical machine or the difference of potentials of a galvanic cell. Moreover the recent rapid development of methods of converting mechanical into electrical energy, through the agency of magneto-electric induction, has made us familiar with the production of currents of great strength associated with great differences of potential. It is, however, not only the introduction of new instruments and apparatus, and the increased power over electrical phenomena that modern experimentalists have thereby acquired, that make it less possible now than formerly to treat of the laws of electric currents without reference to the principles of electrostatics. The cunception that the immediate cause of the phenomena exhibited in either an electric or a magnetic field has its seat, not in electrified conductors, or in magnets or conducting wires, but in an impalpable medium existing throughout space, has completely shifted the scientific point of view as regards electrical effects. What is now demanded of electrical theory is an explanation of the conditions of the medium which are perceptible by us as the properties of an electric or magnetic field. The wider problem of the constitution of the electric medium, whether identical or not with the luminiferous ether, embraces in itself the phenomena of electrostatics, of electric currents, and of magnetism

There was thus every reason to wish that Prof. Wiedemarn might be able to treat electrical science as a whole in the same complete way in which he had previously treated the portions included within the scope of his previous book. This is what he has now undertaken and in great part accomplished. The task is an enormous one, and probably, to any one except the man who has set himself to it, would have seemed overwhelming. Prof. Wiedemann's industry and care, however, never seem to fail before any mass of descriptive detail or complex mathematical discussion, and students of physics may therefore be congratulated upon the near prospect of having from his pen a complete treatise on electricity.

The first of the two volumes already published begins with a section on the General Properties of Electricity, including an historical sketch of early observations, the development of electricity by friction, \&c., electrostatic attraction and repulsion, distribution on conductors, and a description of the various forms of electroscopes and electrometers. Then follows a section on the development of electricity by contact of heterogeneous bodies; next Ohm's law and its applications, the measurement of electrical resistance and of electromotive force, and a 
description of various galvanic elements. These subjects occupy the first volume, consisting of close on 800 pages. The second volume begins with the electrical properties of dielectrics. The section devoted to this subject is erhaps the most interesting in the volume: it contains the mathematical theory of the behaviour of dielectrics, the experimental investigation of specific inductive capacity, the detailed study of electrical machines acting by friction and by induction, together with various allied matters. Next come thermoelectricity, pyroelectricity, and the thermal effects of the discharge of accumulated electricity and of continuous electric currents. After this follows the section devoted to electrochemical action: this occupies about five hundred pages, and concludes with a chapter on the theory of electrification by contact, which completes the volume. It is intended that the whole work should be finished in four volumes, and the manuscript of the two that still remain to be published is for the most part ready.

Prof. Wiedemann's great work has been so long known to physicists that it is needless for us to dwell upon its special qualities farther than to say that it fully retains in its new form all its old characteristics. It is true that it lacks the originality and unity of treatment of Clerk Maxwell's "Electricity and Magnetism," probably the most original systematic treatise on any great branch of physics that was ever written. Nor does it equal in the clearness and elegance of its mathematical discussions the treatise of Mascart and Joubert, a work which, while not laying claim to originality in respect of matter, exhibits in a remarkable degree consecutiveness and lucidity of exposition. Prof. Wiedemann's plan precludes his attaining to these particular excellences in an equal degree. Some sacrifice of unity and consecutiveness is inevitable in a work which aims not only at giving a complete account of what is known respecting a great branch of science, but also at showing what each author has contributed to the stock of knowledge and how he has presented it. From this point of view Prof. Wiedemann's book is without a rival in any language, and is indeed unapproached by any other work.

G. C. F.

\section{FLORA OF HAMPSHIRE}

Flora of Hampshire, including the 1sle of Wight, or a List of the Flowering Plants and Ferns found in the County of Southampton, with Localities of the Less Common Species. By Frederick Townsend, M.A., F.L.S., \&c. Illustrated with Two Plates and a Map. (London : L. Reeve and Co., I883.)

X $\mathrm{E}$ have here an important addition to the already large class of English local floras. To the general botanist, as to people who have made no study of botany, it would seem that the plants of so comparatively small a region as the British Islands must have been catalogued long since, and that there is little to be done in that direction which is worth doing. It certainly is remarkable that, besides facts connected with geographical distribution, which a more minute knowledge of the plants of a country must bring to light, there are actually new plants to be found-new, that is to say, not only to Britain, but to science. A Pondweed (Potamogeton
Griffthii), new to science, has recently been described and figured by Mr. Arthur Bennett in the Journal of Botany, from specimens brought from a mountain lake in North Wales-the only place in the world where it is known to occur. Not that this is the only species peculiar to these islands. To take one example, there is a species of Centaury (Erythrac latifolia), ${ }^{1}$ which has never been found anywhere in the world but on the Lancastrian sandhills; and there it is not known to have been seen more recently than 1865 , if then. In $\mathrm{Mr}$. Townsend's county, a Spearwort (Ramunculus ophioglossifolius), not bitherto found nearer these shores than Jersey, has been detected so lately as to appear only on the very last page of the book; Spartina Townsendi is another case in point; and another example of a plant having been long overlooked, and of which the distribution has quite recently been much extended, will be found in Amm italicum, which was detected in the Isle of Wight in 1854 , and was afterwards found in West Cornwall and Sussex ; this was recorded for Dorset last year, and its range has been extended during the present year to Kent (Folkestone). The volume now before us supplies a good illustration of the way in which novelties miy turn up in the best known districts. Probably if there is one part of England which has been more thoroughly botanised than another it is the Isle of Wight ; yet it was here, and in one of the best known parts - the Downs at Freshwater-that $\mathrm{Mr}$. 'Townsend first distinguished in 1879 an Erythrea (E. capitata, var. spharocephala), which is, as he says, "a peculiariy interesting addition to the British flora. It is," he continues, "a well-marised species, and is not known now to occur anywhere else in the world but in the Isle of Wight and in Sussex. The other form of it was found some fifty years ago somewhere in the neighbourhood of Berlin (the exact locality not being known), and though sought for diligently, it has never been found again."

It will doubtless seem strange to some to learn that a volume of more than 500 closely-printed pages can be occupied by an enumeration of the plants of one English county, especially when it is considered that the pages devoted to descriptions of species are very few. An interesting and instructive article might be written in which the history and development of the local flora should be tracer To undertake such is, however, not our present purpose ; but we may note one or two of the more striking features of these later contributions to local botany, of which the "Flora of Hampshire" is the most recent. One thing to be noticed is their historical nature. Messrs. Trimen and Dyer, in their "Flora of Middlesex" (I 869), were the first to develop this aspect of the work: their method of quoting the first authority for the occurrence of the species as a Middlesex plant has been followed by subsequent writers, and they also did good service by quoting the synonymy of the older (and pre-Linnean) authors-a work which has been very useful to their successors. When it is considered that a book of this kind is mainly undertaken by persons interested in the history of some particular locality, it seems natural that what has been called the antiquarian side of botany should be represented, although there are those who consider that

I The plant so named in Continental floras is certainly not the same as that of the Lancashire sandhills. 